\title{
Isolation system reliability of reinforced concrete building structures
}

\author{
A. C. Teopilus \& I. D. Sidi \\ Institute Technology of Bandung, Indonesia
}

\begin{abstract}
Earthquake-resistant structures are needed, especially in the areas located near a fault of tectonic plates. In the current technological developments, especially in earthquake studies, there are many ways that can be used to minimize even to negate the effects of an earthquake in response of a building, so that the building can still function properly. One of the technological seismic developments is using a base isolation system, which consists of lead rubber bearing, high damping rubber bearings, and others. The working principle of base isolation itself is to increase the period of the structure so that the effects of the earthquake are reduced and this system increases the damping in the structure. Nowadays, a base isolation system is widely used primarily in rigid buildings. It has such a small time period that it becomes an effective system to use.

The main focus of this paper is to determine the reliability of a base isolation system in a 15-story building. It is done by comparing the laboratory results with the results of the analysis of the modelling structure in SAP2000. Base isolation resistance is said to be reliable if resistance is larger than load, which means that base isolation is able to withstand loads that occur, especially earthquake loads that are modelled in time history analysis. In addition, the analysis is also performed to compare the response of a structure using base isolation with a building structure without using a base isolation system, and also to see the energy dissipation from the base isolation building system. The reference that is used as the basis for this plan is SNI 1726-2012 (the Indonesian building code). Keywords: base isolation, high damping rubber bearing, passive damper, isolation reliability, probability of collapse isolator, non linear time history analysis.
\end{abstract}




\section{Introduction}

Nowadays, there are an increasing number of conventional buildings with various architectural techniques, and this results in an increasing need for security and convenience of their uses. In addition, the development in structural designs as well as development in reducing seismic forces caused by earthquakes is also growing. A damper is one alternative that can be used to overcome this problem. The basic idea of a damper is to deamplify the seismic forces transferred into the building, preventing the damage of the structural elements.

In this paper, two building structures were analyzed underground acceleration caused by El Centro earthquake. The first structure was designed using the fixed base system, while the other was designed using base isolation. Both structures were designed using the similar structural dimensions and materials (shown in Figure 1). The structure of a 15-story building with a typical $3.5 \mathrm{~m}$ each floor taller box-shaped symmetrical will be designed using base isolation types of High Damping Rubber Bearing in Jakarta, Indonesia.

This paper discusses the reliability of the base isolation itself which compares the displacement, base shear, and hysteretic curve between a structure without base isolation and a structure using a base isolation system. It starts by defining the basic benefits of isolators and how to design these systems along with the steps that need to be done in designing a base isolation itself. An example of the calculation of the reliability of base isolation using NLTHA (non-linear time history analysis) of various earthquakes will be given. The probability of failure

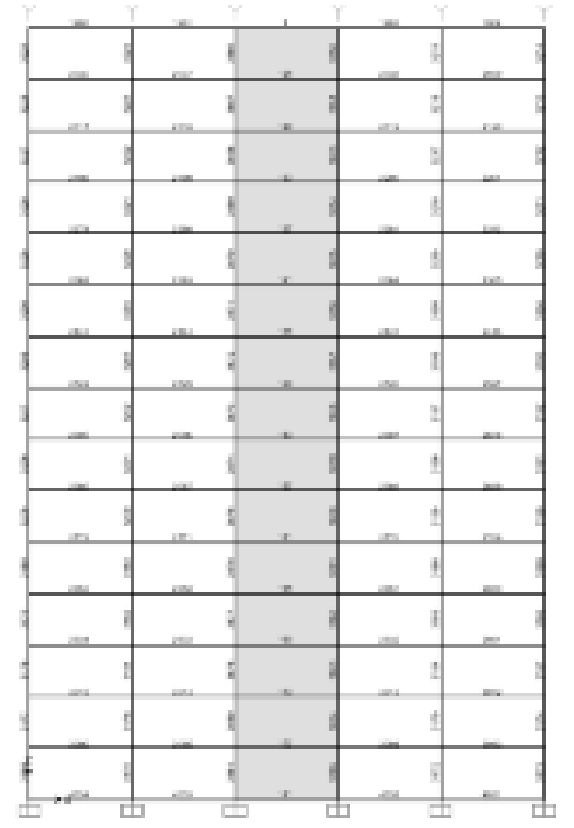

Figure 1: Typical form of structure for analysis. 
of base isolation is also a parameter in the reliability analysis, where the maximum displacement due to the earthquake base isolation would be a benchmark in the distribution probability model.

\section{Base isolation concept}

Base Isolation or often referred to as seismic isolation system is a tool to separate the structure from its foundation, so it can analogized that the structure is separated from the effects of an earthquake. For example, in the structure of a bridge, the superstructure is separated from the column substructure. Base Isolation technology, which has been developed since the $1980 \mathrm{~s}$, is now used in more than 1,000 buildings around the world: in Italy, Japan, USA, and other countries. Base Isolation is included in the general category of passive dampers in buildings (Passive Energy Dissipation). Actually, the concept to separate the structure from the ground, specifically to prevent earthquakes is fairly easy to understand.

Almost all problems in buildings structural design focused to reduce the effects of the earthquake on the buildings. In the design process, there are load cases such as the burden of gravity load, wind, earthquake, and others. To ensure that the structure behaves properly in responding to the loads, the capacity of the structure must not be less than the demand of it.

Earthquakes occur randomly, from the magnitude of earthquake loads to the time and place of the incident, so engineers have to think of how to keep the capacity to withstand earthquake loads. An earthquake causes an inertia force proportional to the mass of a building and the ground acceleration. It is not easy to keep improving the strength of the building. For example, at a high seismic zone, earthquake acceleration can reach 1 or even 2 times the gravitational acceleration. Base isolation takes the opposite approach; the system is trying to reduce the needed resources to withstand an earthquake rather than the building capacity. Earthquakes are not controllable, but the need to resist an earthquake can be developed by preventing the distribution of the seismic forces, that are transmitted from the foundation to the top of the building structure. The main reason for using a base isolation system is, therefore, to anticipate the impact of earthquakes on buildings.

\subsection{Designing base isolation}

Here is the procedure for the system design of the isolator itself. The following steps are done repeatedly until a convergent value is obtained:

a) Choose an isolator size based on a vertical load of the structure and assume a vertical displacement in the period and damping targeted;

b) Calculate the effective stiffness, period, and equivalent viscous damping on the assumed displacement;

c) Of seismic load parameters, calculate the actual displacement for isolator stiffness and damping; 
d) Calculate damping for the actual displacement. Repeat the previous step if necessary;

e) Check and adjust the size of the minimum plan necessary to support insulators loads vertically if needed.

Base isolation used in this analysis, following these steps is HL 075X6R type (Bridgestone product).

\section{Nonlinear time history analysis (NLTHA)}

A MDOF structure when exposed to an acceleration of the ground at the base of the structure shall satisfy the following differential equations:

$$
[\mathrm{m}]\{\ddot{\mathrm{x}}\}+[\mathrm{c}]\{\dot{\mathrm{x}}\}+[\mathrm{k}]\{\mathrm{x}\}=-[\mathrm{m}]\{\mathrm{r}\} \ddot{\mathrm{x}}_{\mathrm{g}}
$$

To scale a record of the motion needs the local spectral response. An earthquake load is scaled to fit the design earthquake from the local spectrum in accordance with the period of the structure.

Under Article 12.3.2 of SNI 1726-2012, earthquake scaling should be done in the period range $0.5 \mathrm{~T}_{\mathrm{D}}$ to $1.25 \mathrm{~T}_{\mathrm{M}}$. As an example of the analysis, a structure using a base isolation system has a period of 3.96 seconds; therefore, the period under review for scaling the earthquake is 1.9 seconds to 5 seconds.

\subsection{Spectrum response based on SNI 1726-2012}

Response spectrum is a spectrum that is presented in the form of graphs/plots between structural vibration period $\mathrm{T}$ and the maximum responses opponent based on the ratio of damping of a certain earthquake. Maximum responses can be maximum deviation (spectral displacement, SD), maximum velocity (spectral velocity, SV) or maximum acceleration (spectral acceleration, SA) of a single degree of freedom (SDOF) structure.

As an example of the spectrum response, Figure 2 shows the Jakarta Spectral calculated in the following steps. Based on SNI 1726-2012, the data used for determining the response spectra are as follows:

1. Select factors risk category building and virtue;

2. Calculate earthquake acceleration parameters;

As an example, in this paper, earthquake spectral response acceleration parameter MCER for short period is $0.69 \mathrm{~g}$ Ss and for short period $\mathrm{S}_{1}$ is $0.29 \mathrm{~g}$.

3. Choose class locations;

4. Compute magnification coefficient of determination factors site;

5. Determine earthquake parameters maximum acceleration and design.

\section{Reliability analysis}

The most important aspect of this reliability analysis is the uncertainty that leads to the failure of the structure of a certain limit boundary. The accuracy of this 


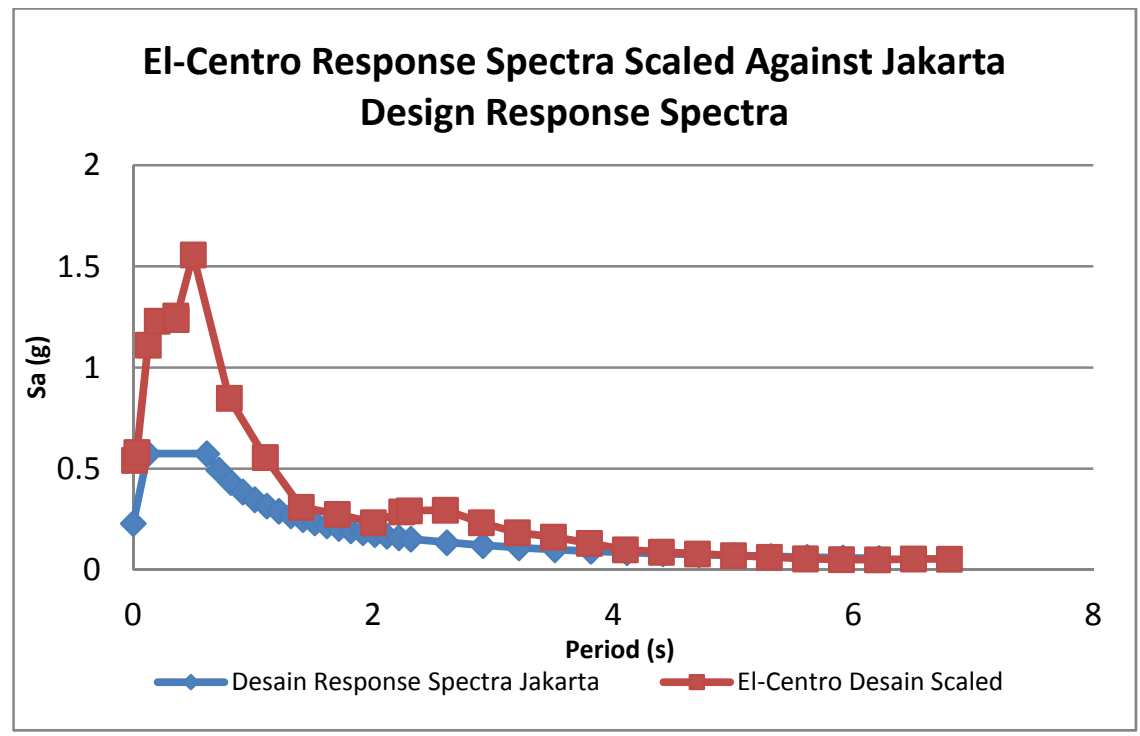

Figure 2: $\quad$ Scaled spectrum design SNI 1726-2012.

analysis depends on the reliability of measurement uncertainty in the accuracy of the analysis. There are 3 things that influence it:

- It is impossible to get all the uncertainties in the analysis, but the most important parts can be identified.

- A method to model and analyze is not easy.

- Analytical formulations are complex, so it is necessary to use a variety of approaches

A simple analysis that can be done to find out the reliability of the base isolation is to consider the effect of the ground motion uncertainty on the response of base isolation as well. Using the formulation of a function of $Z=R-L$, where $R$ is the resistance and $\mathrm{L}$ is the load that occurs, a structure is said to be safe if $Z>0$. Conversely, if $\mathrm{Z}<0$, then failure will occur.

$\mathrm{Z}$ is a normal variable, so the probability of failure can be expressed as follows:

$$
P_{f}=1-\phi\left\{\frac{\ln \frac{\mu_{R}}{\mu_{L}} \sqrt{\frac{1+\delta_{L}^{2}}{1+\delta_{R}^{2}}}}{\sqrt{\ln \left(1+\delta_{R}^{2}\right) \ln \left(1+\delta_{L}^{2}\right)}}\right\}
$$

where $\delta_{L}^{2}$ and $\delta_{R}^{2}$ are the coefficient of variation of L and R. 


\section{Result of studies}

The result of the analysis of the 15-story building is shown in Figure 1. The main goals to be discussed are:

- Comparing the response of the structures including displacement, base shear, as well as energy dissipation obtained from hysteretic curve.

- $\quad$ Finding the value of the probability of failure of the base isolation

By comparing the two structures, the base isolation structure and the fixed base structure, the following analysis is obtained:

- The period of the fixed base structure is 2.18 in mode 1 and mode 2 at 2.12, while in the base isolation structure; the period reaches 3.97 for mode 1 and mode 2 at 3.9. This happens because the base isolation in the building provides a lower stiffness in the overall structure resulting in a longer period of structural shifts. Mode 1 and mode 2 have almost the same period due to the fact that the shape of the structure is symmetric between $\mathrm{x}$ and $\mathrm{y}$ direction.

- The inter story drift of using the base isolation is smaller than the fixed base structure. It proves that the base isolation works as expected because the maximum inter story drift in the structure with the base isolation is only $2 \mathrm{~mm}$, while the fixed base structure results in $7 \mathrm{~mm}$.

- The Structure that is not using the base isolation undergoes plasticity in shear wall boundary and on its logs, while the structure with the base isolation does not undergo plasticity. It is clear that the basic structure of a given isolator does not have the element of plasticity in the structure so that during an earthquake, it remains functional.

- Base shear forces caused by an earthquake that goes into the structure without base isolation is greater than the base shear forces going into the structure of the base isolation. This is because the period of larger structures leads to reduced seismic forces which are absorbed by the structure in accordance with the scaling response spectra that have been made previously. Therefore, the structure of the base shear decreases with the increasing period of the structure. Also, High Damping Rubber Bearing provision reduces the total energy that goes into the structure of $32.71 \%$ for DBE.

For the probability of base isolation failure analysis, the variables taken as a parameter are the maximum displacement of base isolation on the structure of a 15 -story building that has been burdened with 16 kinds of different earthquake record shown in Table 1. To calculate the probability of failure of base isolation in which the definition of failure is $\mathrm{R}<\mathrm{L}$, a function to describe the distribution of a random variable that occurs on the appliance is needed. In this paper, the assumed log normal distribution to the selection distribution is used while checking uses the Kolmogorov-Smirnov test.

\subsection{Load analysis}

Earthquake loads are taken as many as 16 recordings with PGA range from 0.05 $\mathrm{g}$ to $0.94 \mathrm{~g}$. Data retrieved from earthquake recordings Berkley PEER database 
through its official website and recording the earthquake response spectra scaled to Jakarta make sure that the structure that remains undergo plasticity for any given earthquake record. The maximum displacement of base isolation is sought and modeled as a log normal distribution and later the variables are obtained

$$
\begin{gathered}
\xi_{\mathrm{L}}=0.2826 \\
\lambda_{\mathrm{L}}=\mathbf{5 . 5 0 9}
\end{gathered}
$$

This variable will be required in the calculation of the probability of failure of base isolation itself.

Table 1: Earthquakes' ground motion.

\begin{tabular}{|c|c|c|c|c|c|c|}
\hline No & Earthquake & Year & Magnitude & PGA (g) & PGV (cm/sec) & PGD (cm) \\
\hline 1 & Parkfield & 1966 & 6.19 & 0.0597 & 58.369 & 26.13 \\
2 & Northridge & 1994 & 6.69 & 0.101 & 139.779 & 61.783 \\
3 & Impvalley Elcentro & 1979 & 6.53 & 0.1383 & 106.467 & 72.186 \\
4 & Kocaeli & 1999 & 7.51 & 0.2398 & 400.804 & 268.179 \\
5 & Livermore - 01 & 1980 & 5.8 & 0.2406 & 197.048 & 35.244 \\
6 & New Zealand & 1987 & 6.6 & 0.3076 & 211.459 & 40.01 \\
7 & Friuli Italy-01 & 1976 & 6.5 & 0.3857 & 213.583 & 49.049 \\
8 & Kobe Japan & 1995 & 6.9 & 0.4836 & 336.58 & 108.954 \\
9 & chichi & 1999 & 7.62 & 0.5583 & 917.142 & 983.182 \\
10 & Coalinga & 1983 & 6.36 & 0.5904 & 600.591 & 88.416 \\
11 & Gazli & 1976 & 6.8 & 0.5997 & 649.484 & 241.896 \\
12 & Cape Mendocino & 1992 & 7.01 & 0.6148 & 818.727 & 254.838 \\
13 & Landers & 1992 & 7.28 & 0.7165 & 1428.78 & 2.541 .776 \\
14 & Tabas Iran & 1978 & 7.35 & 0.8068 & 1.182 .956 & 968.042 \\
15 & Morgan Hill & 1984 & 6.19 & 0.814 & 622.869 & 101.747 \\
16 & Loma Prieta & 1989 & 6.93 & 0.9439 & 969.567 & 625.464 \\
\hline
\end{tabular}

\subsection{Resistant analysis}

Table 2 indicates the results of laboratory testing of base isolation with different numbers of cycles. From the laboratory test results, impairment of stiffness, damping and hysteretic are found. When base isolation receives periodic load as much as 100 times, the stiffness decreases to $0.75,0.782$ for the damping, and 0.587 for hysteretic from their original conditions. From the results of the laboratory tests, resistant factors can be modeled as a triangular distribution.

\subsection{Probability of failure of base isolation}

According to the modeling of coefficients corresponding decrease in table 2, the average value of the decline can be found. The average stiffness value of 0.83 is used, while the decrease in damping coefficient obtained is 0.89 and a decrease of the total energy obtained is 0.725 . From these results, the average value of the ability of base isolation in deforming the relationship can be concluded in this way: if the stiffness and damping decreases, the ability of displacement 
Table 2: $\quad$ Change rate from reference cycle for X6R Type (Bridgestone technical report).

\begin{tabular}{|c|c|c|c|}
\hline Period & $\mathrm{K}_{\text {eq }}$ & $\mathrm{H}_{\text {eq }}$ & $\Delta W$ \\
\hline 1 & 1.121 & 1.040 & 1.165 \\
\hline 3 & 1.000 & 1.000 & 1.000 \\
\hline 10 & 0.909 & 1.034 & 0.940 \\
\hline 20 & 0.855 & 0.996 & 0.851 \\
\hline 50 & 0.790 & 0.878 & 0.693 \\
\hline 100 & 0.750 & 0.782 & 0.587 \\
\hline
\end{tabular}

increases; whereas if the hysteretic insulator increases, the ability of deforms base isolation also increases according to the eqn. (3).

$$
H_{e q}=\frac{\Delta W}{2 \cdot \pi \cdot K_{e q} \cdot X^{2}}
$$

After obtaining all the necessary coefficients for the load and resistant, we can calculate $\beta$ (beta) to find the probability of collapse of the base isolation itself.

$$
\beta=\frac{\lambda_{\mathrm{R}}-\lambda_{\mathrm{L}}}{\sqrt{\xi_{\mathrm{R}}^{2}+\xi_{\mathrm{L}}^{2}}}
$$

Failure probability can be calculated by finding the $\beta$ (beta) value of the normal distribution table.

$$
P_{f}=\phi(-\beta)
$$

The result of the analysis in this paper, which use a 15-story building with a base isolation system, obtains a beta value of 2,6303. After that, the value of the probability of failure can be searched from eqn. (5).

$$
\begin{gathered}
P_{f}=\phi(-2,6303) \\
P_{f}=1-\phi(2,6303)=1-0,995731 \\
\boldsymbol{P}_{\boldsymbol{f}}=\mathbf{0}, \mathbf{4 2 7} \%
\end{gathered}
$$

The above calculation results show that the probability of failure of base isolation is $0.427 \%$. The obtained results are in accordance with regulations where the probability of structural failure in 50 years is $1 \%$. 


\section{Conclusion}

This paper describes the basis for calculating the reliability of the base isolation along with the probability of failure itself. Preliminary design for the structure and base isolation in this paper is based on SNI 1726-2012, where the rules about the stages that must be considered in designing especially in earthquake territory are explained. This study also takes on several assumptions to facilitate the analysis process, such as the vertical force on each column which is assumed to be uniform so that the base isolation uses only one type. Symmetric structure is also designed to ease the process of analyzing; for further analysis, the structure is not symmetrically designed to see the effect of torque on base isolation that occurs in buildings

From the study of reliability, it can be concluded that the base isolation is very useful in absorbing earthquake energy generated at the building (conventional building), especially in maintaining the structural elements to prevent damage in an earthquake. Base isolation on a building influences the displacement of the building, so the structure can still function although an earthquake happens because it is made of rubber which has a large displacement. This can be seen from a given energy dissipation and inter story drift of the building itself when the earthquake happens.

In the seismic reliability analysis of structures, uncertainties of the earthquake or ground intensity parameters are considered as to affect the reliability estimates significantly and to assume more importance over other uncertainties. As a result, the seismic reliability analysis of the structures is found to be mostly carried out by considering the randomness of the ground motion, the uncertainties inherent in the occurrence of an earthquake and in defining its different intensity parameters. In addition, the response of the structure is also one uncertainty caused due to the earthquake loads. Therefore, to improve the accuracy of the analysis, a lot of data, from the laboratory as well as from the testing of the model design, are needed. These data will provide a more accurate analysis.

\section{References}

[1] SNI 1726-2012 Standar Perencanaan Ketahanan Gempa untuk Struktur Gedung dan non Gedung (Indonesian Standard Code).

[2] SNI 03-2847-2002. Tata Cara Perhitungan Struktur Beton Untuk Bangunan Gedung. Indonesian Standard Code.

[3] Bridgestone Corporation. High Damping Rubber Bearings for Base Isolation. Technical Report(HDR-X0.6R).

[4] Bridgestone. Design Characteristics of High Damping Rubber Bearing.

[5] Datta, T.K. Seismic Analysis of Structures. Wiley, Singapore. 2010

[6] Ang, Alfredo H-S and Tang, W.H. Probability Concepts in Engineering. Volume 1. 1975.

[7] Cheng, F.Y.,Jiang H., and Lou K. Smart Structures - Innovative Systems for Seimsic Response Control. CRC Press. 
[8] Wang, C.K. Intermediate Structural Analysis. McGraw-Hill. 1983.

[9] ATC 402. Seismic Evaluation and Retrofit of Concrete Buildings. Volume 1. Seismic Safety Commission, California. 1996. 